\title{
Crystallization Solvent Design Based on a New Quantitative Control Model of Crystal Morphology
}

\author{
Shiyang Chai ${ }^{1}$, Enhui $\mathrm{Li}^{1}$, Lei Zhang ${ }^{1}$, Jian $\mathrm{Du}^{1}$, and Qingwei Meng${ }^{1}$ \\ ${ }^{1}$ Dalian University of Technology
}

May 26, 2021

\begin{abstract}
Solution crystallization is an important separation unit operation in active pharmaceutical ingredient (API) production. Solvent is one of the important factors affecting crystal morphology. How to select/design suitable crystallization solvents is still one of the most urgent problems in the crystallization field. In this paper, a framework for crystallization solvent design based on the developed quantitative control model of crystal morphology is proposed. First, molecular dynamics is used to predict the crystal morphology in solvents. Next, nine solvent descriptors are selected. Then, the quantitative relationship between crystal aspect ratio and solvent descriptors is developed. Subsequently, Computer-Aided Molecular Design (CAMD) method is integrated with the developed quantitative control model. The crystallization solvent design problem is expressed as a Mixed-Integer Non-Linear Programming (MINLP) model, which is solved by the decomposition algorithm. Finally, the crystallization solvent design framework is applied to two cases: benzoic acid and ibuprofen, and experimental verification is implemented.
\end{abstract}

\section{Hosted file}

Manuscript.docx available at https://authorea.com/users/415960/articles/523707crystallization-solvent-design-based-on-a-new-quantitative-control-model-of-crystalmorphology 